\title{
Occurrence and Fate of Natural Estrogens in Swiss Cattle and Pig Slurry
}

Daniela Rechsteiner, Sabine Schrade, Michael Zähner, Michael Müller, Juliane Hollender, and Thomas D. Bucheli*

Cite This: J. Agric. Food Chem. 2020, 68, 5545-5554

Read Online

ACCESS |

Llll Metrics \& More

Article Recommendations

Supporting Information

ABSTRACT: Natural estrogens act as endocrine disruptors. However, the fate of livestock farming derived natural estrogens (17 $\alpha$ estradiol, $17 \beta$-estradiol, estrone, and estriol) in slurry is not well understood. In this study, we assessed the effects of on farm-storage on natural estrogen concentrations in slurry. Furthermore, we monitored pig and cattle slurry pits from major agricultural areas in Switzerland and determined natural estrogen concentrations therein. They were relatively stable over time, and mean concentrations ranged from 138 to 861 and 54 to $244 \mathrm{ng} / \mathrm{L}$ for cattle and pig slurries, respectively. $17 \alpha$-Estradiol and estriol were the most prevalent estrogens in cattle and pig slurries, respectively. Based on livestock numbers, agricultural area, and estrogen concentrations in slurry, the estimated annual load of total natural estrogens applied on agricultural area amounted to $36 \mathrm{mg} / \mathrm{ha}$. Our results indicate that slurry application is a relevant source of natural estrogens in the environment.

KEYWORDS: agriculture, manure, steroid hormones, livestock farming, endocrine disruption

\section{INTRODUCTION}

Naturally produced estrogen hormones such as $17 \alpha$-estradiol $(\mathrm{E} 2 \alpha), 17 \beta$-estradiol (E2 $\beta)$, estrone (E1), and estriol (E3) act as endocrine disrupting chemicals in the environment. Especially for aquatic organisms, elevated estrogen concentrations in surface waters have severe effects on their reproduction and development. ${ }^{1,2}$ Husbandry animal slurry application to agricultural area results in natural estrogen emissions to surface waters, ${ }^{3,4}$ but its contribution to the total estrogen load in surface waters remains unknown. ${ }^{5}$ Among the major mammal groups in Switzerland, 59.6\% are humans (8544527 individuals), ${ }^{6} 22.0 \%$ are livestock animals (3 153 387), ${ }^{6} 16.5 \%$ are domestic animals including dogs, cats, and rabbits $(2366000),{ }^{7}$ and approximately $1.9 \%$ are wild animals such as deer (265 749). ${ }^{8}$ Consequently, over all nonhuman mammals, livestock animals are expected to contribute the most to the total urinary and fecal excretion quantities. Among them, cattle and pigs are dominating in Switzerland. ${ }^{6}$ Particularly female farm animals produce and excrete estrogens during pregnancy and cycling. The main estrogens produced during pregnancy of cattle are E2 $\alpha$ and E1 and during pregnancy of pig mainly $\mathrm{E} 1$ production is increased. During cycling E2 $\beta$ production increases in cattle and pigs. ${ }^{9}$ Based on Johnson et al. ${ }^{5}$ and livestock and inhabitant numbers of Switzerland, ${ }^{6}$ we estimated that cattle and pigs in Switzerland excrete approximately one order of magnitude more estrogens (120 kg/year E2 $\beta$ and $324 \mathrm{~kg} /$ year E1) than humans $(21 \mathrm{~kg} /$ year E2 $\beta$ and $31 \mathrm{~kg} /$ year E1; Supporting Information (SI, Table S1).

In previous studies, $\mathrm{E} 2 \alpha, \mathrm{E} 2 \beta, \mathrm{E} 1$, and $\mathrm{E} 3$ concentrations in liquid cattle, pig, and poultry manure and slurry ranged from nondetected to $74700 \mathrm{ng} / \mathrm{L} .^{10-16}$ Under anaerobic or anoxic conditions, estrogen concentrations remain relatively con- stant. $^{17,18}$ In contrast, under aerobic conditions, natural estrogens are mainly removed by microbial degradation in slurry. ${ }^{19,20} 17 \alpha$-Estradiol and E2 $\beta$ are transformed to E1, which is further transformed to E3. ${ }^{13}$ However, the transformation of $\mathrm{E} 2 \alpha$ and $\mathrm{E} 2 \beta$ to $\mathrm{E} 1$ is reversible under anaerobic conditions. ${ }^{17}$ Effects of slurry storage on estrogen concentrations were mainly studied in the laboratory, ${ }^{17,21,22}$ while knowledge about their fate in full scale, real world housing systems is scarce. Our first goal was to investigate the effect of storage in different parts of a typical Swiss dairy housing on concentrations and compositions of E2 $\alpha, \mathrm{E} 2 \beta, \mathrm{E} 1$, and E3 in slurry. Furthermore, we compared measured estrogen amounts in the slurry storage compartments with estimated estrogen excretion loads of the cattle herd in the studied dairy housing.

Estrogen prevalence in slurry has been studied mainly outside Europe. ${ }^{10,11,13}$ Unlike North America, storage of liquid slurry in slurry lagoons is uncommon in the European Union. Among all agricultural holdings in the European Union in 2010 , $82 \%$ had storage facilities for solid dung, 35\% had storage facilities for liquid manure, $25 \%$ had slurry tanks, and only $5 \%$ had slurry lagoons. Farms with slurry lagoons were mainly located in Spain and The Netherlands. ${ }^{23}$ In Switzerland, all farms are obliged to store liquid manure in slurry pits lined with concrete below or above ground. Slurry pits have to be covered with solid constructions, e.g., a concrete ceiling, or floating foils to prevent air pollution. ${ }^{24}$ In general, farm sizes

Received: February 7, 2020

Revised: $\quad$ May 1, 2020

Accepted: May 4, 2020

Published: May 4, 2020 
and consequently also stored slurry volumes are smaller in Switzerland compared to North America. ${ }^{6,25}$ Therefore, we presume that microbiology, temperature, and physicalchemical parameters are different in Swiss slurry pits compared to slurry lagoons, which, in turn, might influence natural estrogen concentrations in slurry. To assess this assumption, a nationwide slurry monitoring was conducted to quantify average natural estrogen concentrations and compositions in liquid cattle and pig slurry in Switzerland.

Whereas in Switzerland estrogens in human wastewater are mostly eliminated in wastewater treatment plants (WWTP) through biological degradation and recently also additional treatments with ozone or activated carbon, ${ }^{26}$ agriculturally derived estrogens are directly or in the form of solid and liquid slurry emitted to the agricultural area. For pigs, we can assume that most excretions are collected in slurry pits, because it is allowed and customary to keep pigs indoors without access to pastures in Switzerland. ${ }^{27}$ Around 50\% of the pigs housings have outdoor yards, from which the excrements also gets into slurry pits. ${ }^{28}$ Cattle are estimated to graze around 1 to $34 \%$ of the year on pastures. ${ }^{29}$ Consequently, up to one-third of the natural estrogen excretions are directly emitted on pastures. Determination of mean estrogen concentrations in both relatively fresh and aged liquid Swiss cattle and pig farm slurries allowed first to better estimate the annual estrogen loads emitted to agricultural area through both direct excretion and slurry application for Switzerland and second to compare them with data from the United States ${ }^{13,14,18}$ and New Zealand. ${ }^{11}$ As livestock density (on average 1.3 livestock units (LSU)/ha) in Switzerland is in the top third of all European countries (0.2-3.8 LSU/ha, mean of all 28 European countries: $0.8 \mathrm{LSU} / \mathrm{ha}),{ }^{6,23}$ we suppose that slurry-derived estrogen emissions to agricultural area are at the higher end in Switzerland in comparison to other European countries. In addition, it was estimated that $55 \%$ of the Swiss agricultural area is potentially connected with surface waters ${ }^{30}$ and hence slurry-derived natural estrogens are possibly contaminants of concern in surface waters.

\section{MATERIALS AND METHODS}

Chemicals. $17 \alpha$-Estradiol-16,16,17- $\mathrm{d}_{3} \quad\left(\mathrm{E} 2 \alpha-\mathrm{d}_{3}\right)$ was obtained from BOC Sciences (Shirley, U.S.A.). Estriol-3,16,17- $\mathrm{d}_{3}\left(\mathrm{E} 3-\mathrm{d}_{3}\right)$ was bought from Toronto Research Chemicals Inc. (North York, Canada). Additionally, E1, Estrone-2,4,16,16- $\mathrm{d}_{4}\left(\mathrm{E} 1-\mathrm{d}_{4}\right), \mathrm{E} 2 \alpha, \mathrm{E} 2 \beta$, $17 \beta$-estradiol-16,16,17- $\mathrm{d}_{3}\left(\mathrm{E} 2 \beta-\mathrm{d}_{3}\right)$, and $\mathrm{E} 3$, all in $1000 \mu \mathrm{g} / \mathrm{mL}$ methanol, were purchased from A2S (Saint Jean d'Illac, France). Other chemicals used for chemical analyses are listed in the SI, Chapter 3.

Slurry Sampling. Slurry samples were collected from one housing part of the experimental dairy housing for emission measurements of Agroscope Taenikon, Switzerland $\left(47^{\circ} 49^{\prime} \mathrm{N}, 8^{\circ} 92^{\prime} \mathrm{E}\right.$, around $550 \mathrm{~m}$ a.s.l.). ${ }^{31}$ The housing part consists of three rows of cubicles with straw mattresses and solid floors with rubber mats as well as an outdoor exercise area with solid concrete flooring (Figure 1). Stationary scrapers removed dung from the feeding aisle and the cubicle access area to the cross channel section $\left(23.4 \mathrm{~m}^{3}\right)$ 3-12 times a day. Dung was removed manually from the outdoor exercise area with a scraper every couple of days. Due to ammonia, methane and carbon dioxide emission measurements, which were conducted in parallel, cows had access to the outdoor exercise area only on defined days of our sampling period. The slurry pit $\left(252.2 \mathrm{~m}^{3}\right)$ is under ground and covered with a concrete ceiling, which contains four opening holes. A detailed schematic diagram of the experimental dairy housing in Taenikon is shown in the SI, Figure S3.

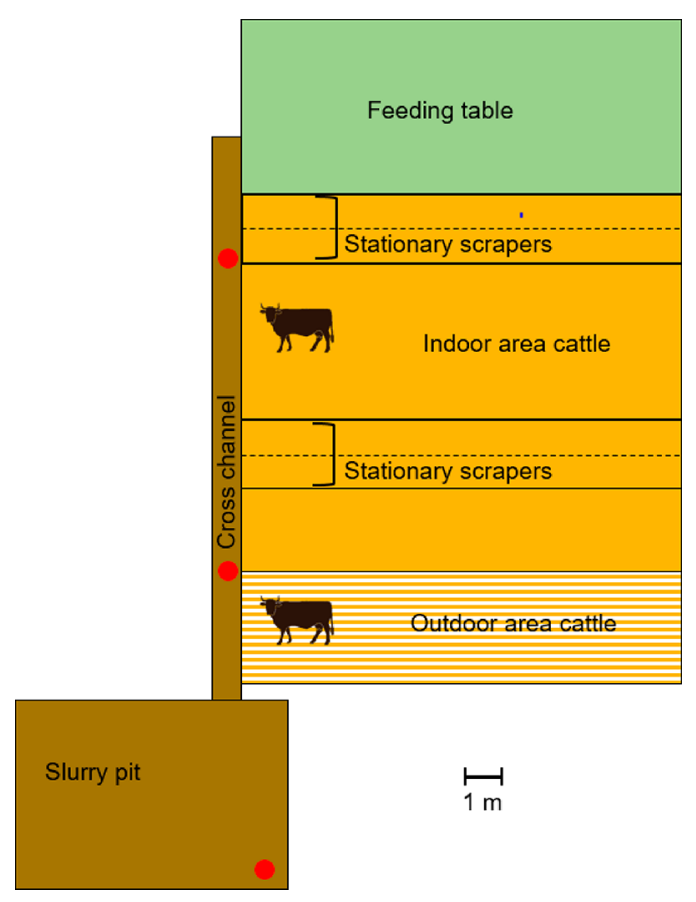

Figure 1. Horizontal plan of one part of the experimental dairy housing in Taenikon, Switzerland. The animals could move freely in the indoor and outdoor cattle area. Dung from the indoor area (bright brown) was pushed with stationary scrapers 3-12 times a day to the cross channel $\left(23.4 \mathrm{~m}^{3}\right.$; dark brown). Dung from the outdoor area was removed manually to the cross channel. Slurry was further transferred from the cross channel to the slurry pit $\left(252.2 \mathrm{~m}^{3}\right)$ every fifth to tenth day. Slurry sampling locations along the cross channel and in the slurry pit are illustrated with red dots. A more detailed scheme of the experimental dairy housing in Taenikon is presented in the SI, Figure S3. Credit for the cows copyright American Chemical Society.

During our sampling period 18-20 lactating cows (Brown Swiss and Swiss Fleckvieh breeds represented around $45 \%$ and $40 \%$, respectively, of all cattle kept in Switzerland in $2013^{32}$ ) were kept in the housing part in accordance with the Swiss animal welfare act. ${ }^{33}$ We knew pregnancy duration of every cow on each experimental day. Their diet consisted of grass silage, maize silage, hay, sugar beet pulp, and concentrates. Cows were only treated with antibiotics in case of medical reasons.

Slurry samples were taken from the cross channel and the slurry pit every 5-10 days from June 2017 until October 2017. Slurry in the slurry pit was removed prior to the experiment and was not emptied during the experimental period. According to Swiss regulation, every farm must have slurry storage facilities with a capacity for at least five months. ${ }^{34}$ Furthermore, it is not allowed to apply slurry on snowcovered or frozen soil. ${ }^{35}$ Therefore, slurry storage periods range in Switzerland from 3-6 months. Additionally, we sampled slurry from the cross channel at a higher frequency, i.e., daily for the first 10 days, to assess estrogen dissipation and transformation in the cross channel before its removal to the slurry pit. Slurry was sampled at two separate sections of the cross channel, subsamples were merged in a $20 \mathrm{~L}$ vessel and mixed with a kitchen blender, and aliquots of it were distributed into three $1 \mathrm{~L}$ alumina bottles. We conducted the slurry sampling with a tube-like device (approximately $3 \mathrm{~L}$ volume, $3 \mathrm{~m}$ long) (SI, Figure S4). Immediately afterward, the cross channel slurry was flushed to the slurry pit. The slurry in the pit was homogenized for $30 \mathrm{~min}$ before sample collection. For safety reasons, we took three subsamples from only one opening hole of the slurry pit. Subsamples were merged in a $20 \mathrm{~L}$ vessel and mixed with a kitchen blender. Aliquots of the mixed subsamples were filled into three $1 \mathrm{~L}$ alumina 


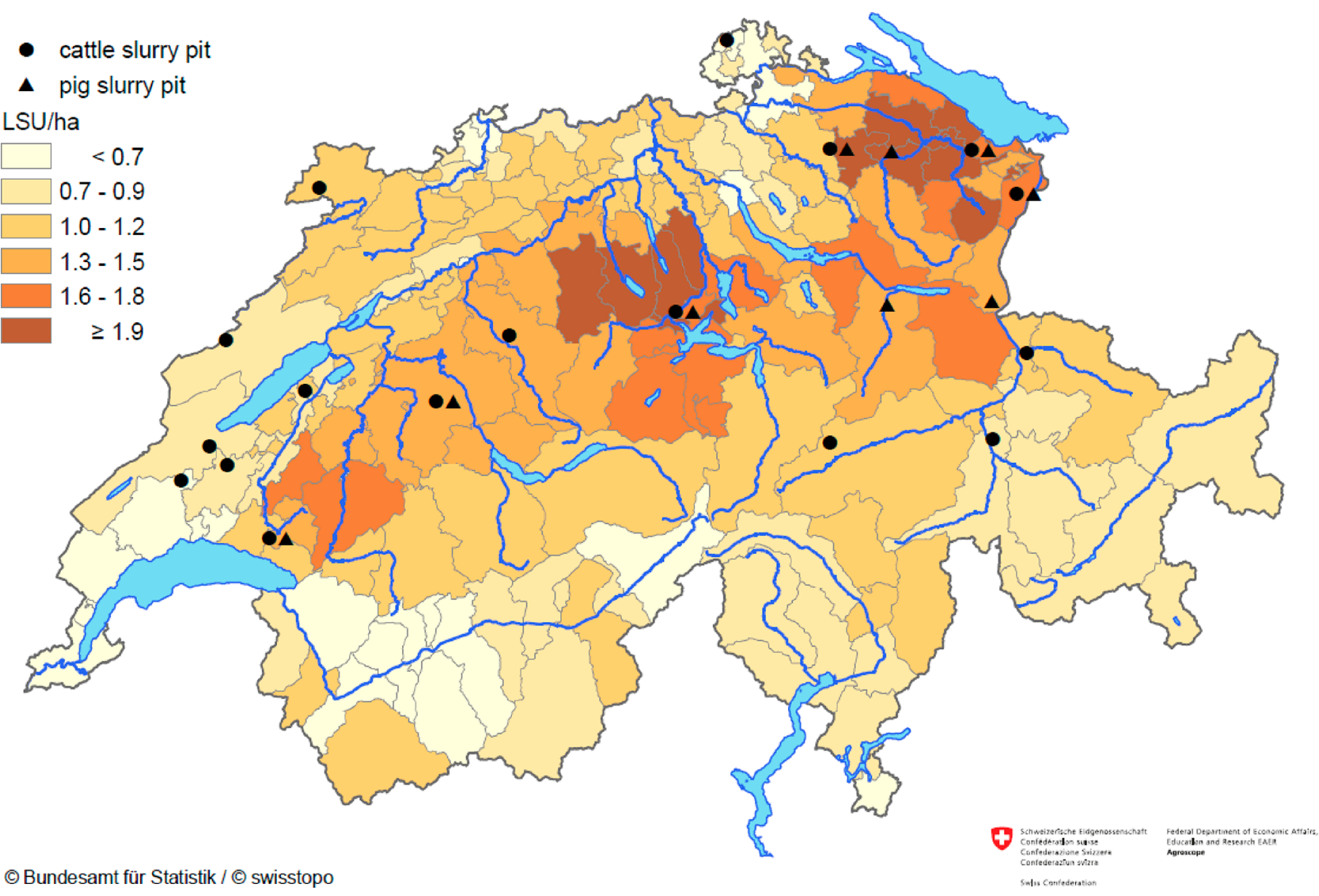

Figure 2. Locations of the monitored farms: cattle (black circles) and pig (black triangles) slurry pits. For every Swiss district livestock units (LSU) per hectare are indicated (based on data from the Swiss Federal Office for Statistics ${ }^{6}$ ). The locations of farms and LSU per hectare were joined to landscape models, which contained administrative units, national boundaries and natural features such as watercourses and lake contours of Switzerland (Source: "Swiss Federal Office of Topography"). ${ }^{53}$

bottles. The alumina bottles were transported to the laboratory in a cooling box and frozen at $-20{ }^{\circ} \mathrm{C}$ until sample processing.

To monitor natural estrogens in Swiss slurries, we collected samples in slurry pits of nine pig fattening farms and 17 dairy and/or cattle fattening farms. Farms were located in different topographic regions, altitudes and areas with different livestock densities (Figure 2). In addition, forage, animal husbandry systems, and production systems differed among the farms. Domestic wastewater was collected in slurry pits of half of the studied farms. However, in comparison to slurry loads produced by livestock animals, domestic wastewater contributions were marginal. We used the same tube-like device as in Taenikon to collect samples from the slurry pits in the slurry monitoring (SI, Figure S4). From every slurry pit we took ten subsamples and merged them in a $35 \mathrm{~L}$ vessel. Slurry was stirred with a kitchen blender and an aliquot was filled into a $1 \mathrm{~L}$ alumina bottle. The procedure was repeated once. We transported the duplicate samples to the laboratory in a cooling box and froze them at $-20{ }^{\circ} \mathrm{C}$ until sample extraction.

Extraction QuEChERS. Frozen slurry samples $\left(-20^{\circ} \mathrm{C}\right)$ were left to adjust to room temperature. Homogenized liquid slurry ( $5 \mathrm{~g}$ ) was extracted using the QuEChERS method, ${ }^{36}$ with slight modifications. Acetonitrile $(15 \mathrm{~mL})$ and $6.5 \mathrm{~g}$ of a salt mixture consisting of $4 \mathrm{~g}$ of magnesium sulfate, $1 \mathrm{~g}$ of sodium chloride, $0.5 \mathrm{~g}$ of disodium hydrogen citrate, and $1 \mathrm{~g}$ of trisodium citrate dehydrate and internal standard (1.5 ng, i.e., $150 \mu \mathrm{L} 10000 \mathrm{ng} / \mathrm{L}$ internal standard mixture of $\mathrm{E} 1-\mathrm{d}_{4}, \mathrm{E} 2 \alpha-\mathrm{d}_{3}, \mathrm{E} 2 \beta-\mathrm{d}_{3}$, and E3- $\mathrm{d}_{3}$ in acetonitrile) was added to the liquid slurry subsample. Subsequently, the subsample was vortexed for $30 \mathrm{~s}$, placed on an orbital shaker for $5 \mathrm{~min}$, and centrifuged for $5 \mathrm{~min}$ at $3000 \mathrm{rpm}$. The supernatant $(5 \mathrm{~mL})$ was transferred and $1.2 \mathrm{~g}$ of a cleanup mixture (150 mg of PSA silica bulk, $150 \mathrm{mg}$ of LiChrolut RP-
$18(40-63 \mu \mathrm{m})$, and $900 \mathrm{mg}$ of magnesium sulfate) was added. After the addition of the cleanup mixture the sample was vortexed, shaken, and centrifuged for a second time. An aliquot of the supernatant (1 $\mathrm{mL}$ ) was filtered with a $0.2 \mu \mathrm{m}, 13 \mathrm{~mm}$ diameter PTFE filter. The filtrate was evaporated to complete dryness with $\mathrm{N}_{2}$ and derivatized afterward.

Derivatization. We derivatized the samples as outlined by Anari et al. ${ }^{37}$ and Backe et al. ${ }^{38}$ Briefly, samples were reconstituted in 200 $\mu \mathrm{L}$ of $50 \mathrm{mM}$ sodium carbonate ( $\mathrm{pH} 11)$ in water and $400 \mu \mathrm{L}$ of 0.1 $\mathrm{mg} / \mathrm{mL}$ dansyl chloride in acetone was added. Subsequently, we vortexed the sample and placed the reconstituted samples for $15 \mathrm{~min}$ in a sand bath in an oven at $60^{\circ} \mathrm{C}$. Vortexing and thermal incubation was repeated. Analytes were phase transferred into $1 \mathrm{~mL}$ of MTBE. The supernatant, consisting largely of MTBE, was collected with a Pasteur pipet. Afterward, the MTBE supernatant was heated and simultaneously evaporated to complete dryness under a gentle stream of $\mathrm{N}_{2}$. The sample was reconstituted with $1 \mathrm{~mL}$ of $40 \%$ acetonitrile in water.

Natural Estrogen Analysis. A Poroshell 120 Phenyl-Hexyl column $(2.1 \times 50 \mathrm{~mm}, 2.7 \mu \mathrm{m}$, Agilent (Basel, Switzerland)) was used for natural estrogen separation. The following elution gradient was applied: $50 \% \mathrm{~B}(50 \% \mathrm{~A})$ at $0 \mathrm{~min}, 65 \% \mathrm{~B}(35 \% \mathrm{~A})$ at $6 \mathrm{~min}, 100 \%$ $\mathrm{B}(0 \% \mathrm{~A})$ at $6.2 \mathrm{~min}, 100 \% \mathrm{~B}(0 \% \mathrm{~A})$ at $12 \mathrm{~min}, 50 \% \mathrm{~B}(50 \% \mathrm{~A})$ at $14.5 \mathrm{~min}$, and $50 \% \mathrm{~B}(50 \% \mathrm{~A})$ at $17 \mathrm{~min}$. Eluent A consisted of water with $0.1 \%$ formic acid and eluent B was acetonitrile with $0.1 \%$ formic acid. ${ }^{39}$ The injection volume was set to $50 \mu \mathrm{L}$ and mobile phase flow rate was $0.45 \mathrm{~mL} / \mathrm{min}$. The column temperature was $30^{\circ} \mathrm{C}$.

Analyte detection was conducted with positive electrospray ionization tandem mass spectrometry on an Agilent 6470 QQQ LC-MS/MS (Basel, Switzerland) instrument in dynamic multiple- 

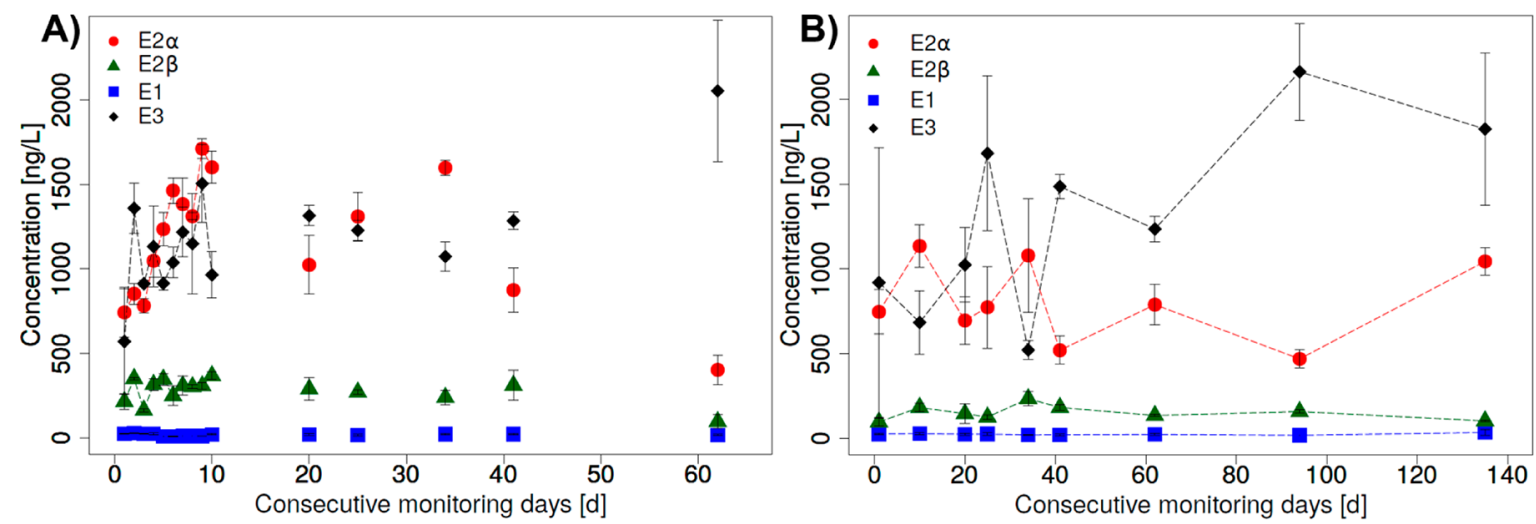

Figure 3. Concentration of nonconjugated natural estrogens: $17 \alpha$-estradiol (E2 $\alpha$, red circles), $17 \beta$-estradiol (E2 $\beta$, green triangles), estrone (E1, blue squares), and estriol (E3, black diamonds) in slurry cross channel (A; accumulated over five to 10 days, and then discharged into the slurry pit) and slurry pit (B; accumulated continuously over 134 days) in a part of the experimental dairy housing in Taenikon, Switzerland (Figure 1). Error bars represent the standard deviation among the triplicate of subsamples.

reaction monitoring $(\mathrm{dMRM})$. The following interface parameters were used for the LC-MS/MS system: gas temperature $\left(\mathrm{N}_{2}\right.$, purity $>99 \%$ ), $325{ }^{\circ} \mathrm{C}$; gas flow, $7 \mathrm{~L} / \mathrm{min}$; nozzle voltage, $0 \mathrm{~V}$ positive and 0 $\mathrm{V}$ negative; nebulizing gas, $55 \mathrm{psi}$; capillary voltage, $3500 \mathrm{~V}$ positive and $0 \mathrm{~V}$ negative; sheath gas temperature, $200{ }^{\circ} \mathrm{C}$; sheath gas flow, 11 $\mathrm{L} / \mathrm{min}$; cell accelerator voltage, $5 \mathrm{~V}$. The run time of a single sample was $17 \mathrm{~min}$. Retention times, precursor and product ions, fragmentor voltage and collision energies are listed in the SI (Table S2). Quantification of the analytes was performed by internal standard calibration. Data processing was executed with Agilent QQQ Quantitative Analysis program. As the dry matter content of in the liquid slurry samples was only around $4 \%$ (SI, Table S6), we assumed that slurry had the density of water and presented the final concentration of slurry samples in $\mathrm{ng} / \mathrm{L}$.

Method Validation Natural Estrogens. The determination of analyte's limits of detection (LOD), limits of quantification (LOQ), ion suppression, instrument and method precision, and relative and absolute recovery is explained in detail in the SI (SI; Chapter 5). Values obtained for these quality assurance and quality control parameters were as follows: LOD: $\mathrm{E} 2 \alpha=1.3 \mathrm{ng} / \mathrm{L}, \mathrm{E} 2 \beta=6.3 \mathrm{ng} / \mathrm{L}$, $\mathrm{E} 1=4.3 \mathrm{ng} / \mathrm{L}$, and E3 = $1.4 \mathrm{ng} / \mathrm{L} ; \mathrm{LOQ}: \mathrm{E} 2 \alpha=4.5 \mathrm{ng} / \mathrm{L}, \mathrm{E} 2 \beta=20.8$ $\mathrm{ng} / \mathrm{L}, \mathrm{E} 1=14.2 \mathrm{ng} / \mathrm{L}$, and E3 $=4.8 \mathrm{ng} / \mathrm{L}$; ion suppression: $\mathrm{E} 2 \alpha=0 \%$, $\mathrm{E} 2 \beta=-2 \%, \mathrm{E} 1=-20 \%$, and $\mathrm{E} 3=-10 \%$. Absolute and relative recoveries were for all substances between 80 and $120 \%$ (absolute recovery: $\mathrm{E} 2 \alpha=118 \%, \mathrm{E} 2 \beta=110 \%, \mathrm{E} 1=108 \%$, and $\mathrm{E} 3=111 \%$; relative recovery: $\mathrm{E} 2 \alpha=92 \%, \mathrm{E} 2 \beta=100 \%, \mathrm{E} 1=109 \%$, and $\mathrm{E} 3=$ $105 \%$ ). Method precision (extraction of five subsamples of a slurry sample with the concentration E2 $\alpha=1606 \mathrm{ng} / \mathrm{L}, \mathrm{E} 2 \beta=200 \mathrm{ng} / \mathrm{L}, \mathrm{E} 1$ $=164 \mathrm{ng} / \mathrm{L}$ and E3 $=118 \mathrm{ng} / \mathrm{L})$ was E2 $\alpha=8 \%, \mathrm{E} 2 \beta=7 \%, \mathrm{E} 1=15 \%$, and $\mathrm{E} 3=8 \%$. Instrument precision (five repeated measurements of one slurry subsample extracted for determination of method precision) was $\mathrm{E} 2 \alpha=5 \%, \mathrm{E} 2 \beta=6 \%, \mathrm{E} 1=5 \%$, and $\mathrm{E} 3=9 \%$. Analysis of variances between samples, subsamples, and analytical replicates revealed that it was highest for the first, indicating that it originated mainly from differences in farming, housing, and/or slurry pit systems.

Spatially Resolved Agriculturally Derived Natural Estrogen Emissions to Agricultural Soil. We combined land use data with a resolution of $100 \mathrm{~m}$ (Arealstatistik, Swiss Federal Statistical Office, 2017 $)^{40}$ with livestock numbers ${ }^{6}$ and measured mean estrogen concentrations in Swiss slurry to estimate the annual load of natural estrogens applied on agricultural area in Switzerland using $R^{41}$

Statistical Analysis. All statistical analyses were conducted in $\mathrm{R}^{41}$ Continuous variables are summarized by their means and standard deviations.

\section{RESULTS AND DISCUSSION}

Natural Estrogen Concentrations in a Dairy Housing System. Concentrations of nonconjugated $\mathrm{E} 2 \alpha, \mathrm{E} 2 \beta, \mathrm{E} 1$, and E3 in the slurry cross channel and in the slurry pit of an experimental dairy housing part in Taenikon, Switzerland were monitored over 62 and 134 days, respectively (Figure 3). All natural estrogens were detected in all slurry samples collected in the dairy housing in Taenikon. In the cross channel the predominant estrogens were $\mathrm{E} 2 \alpha$ and $\mathrm{E} 3$, followed by $\mathrm{E} 2 \beta$ and E1 (Figure 3A). The first 10 days (i.e., the first batch of slurry in this intermediate slurry storage channel) were sampled at higher frequency on a daily basis as this specific slurry batch built up and revealed an increase of E2 $\alpha$ concentrations. Except for the last slurry batch of the cross channel (day 62), samples taken successively at the end of intervals of 5 to 10 days (day 20 to 41 ) showed relatively constant natural estrogen concentrations (fluctuations by factors two to four for all analytes) in the individual batches of slurry in the cross channel. At monitoring day 62, E2 $\alpha$ and E1 concentrations decreased, E 3 concentration increased, and E2 $\beta$ concentration remained constant. Excretion of mainly E2 $\alpha$ and, to a smaller extent, of E1 and E2 $\beta$ is augmented toward the end of pregnancy. ${ }^{42}$ At monitoring day 62 , the cow herd had less individuals at the end of their pregnancy, which was reflected in decreased E2 $\alpha$ and E1 concentrations in the slurry cross channel.

Natural estrogen concentrations in slurry from the slurry pit were in general comparable with those in the cross channel, with the exception of systematically lower numbers for E2 $\beta$ (Figure 3B). Comparable to the observations in the cross channel (Figure 3A), E1 concentrations were lowest and remained stable in the slurry pit (Figure 3B). The concentration E2 $\alpha$ was constant in the slurry pit (Figure 3B) and fluctuated in the same order of magnitude as in the cross channel (Figure 3A). Estriol, which is a metabolite of E2 $\alpha$, $\mathrm{E} 2 \beta$, and $\mathrm{E} 1{ }^{13}$ was the predominant estrogen in the slurry pit (Figure 3B). Moreover, a weak trend toward augmented E3 concentrations with longer slurry storage duration was observable. Overall, except for E3 concentrations after 80 days of storage, natural estrogen concentrations in the studied slurry pit remained relatively stable over a measurement period of 134 days.

Our findings are consistent with the study of NogueraOviedo et al., ${ }^{18}$ which showed that the total steroid hormone 
A)
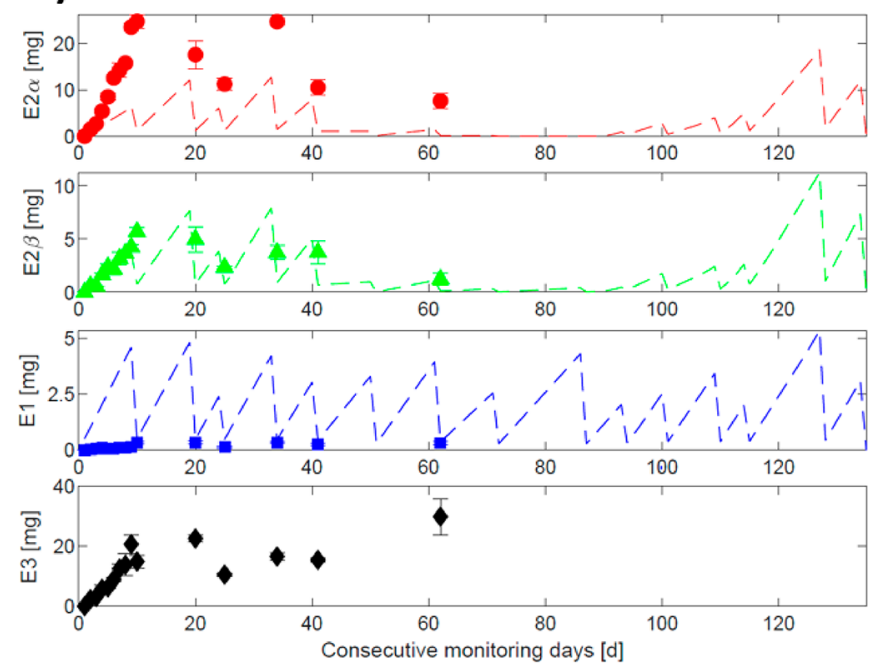

B)

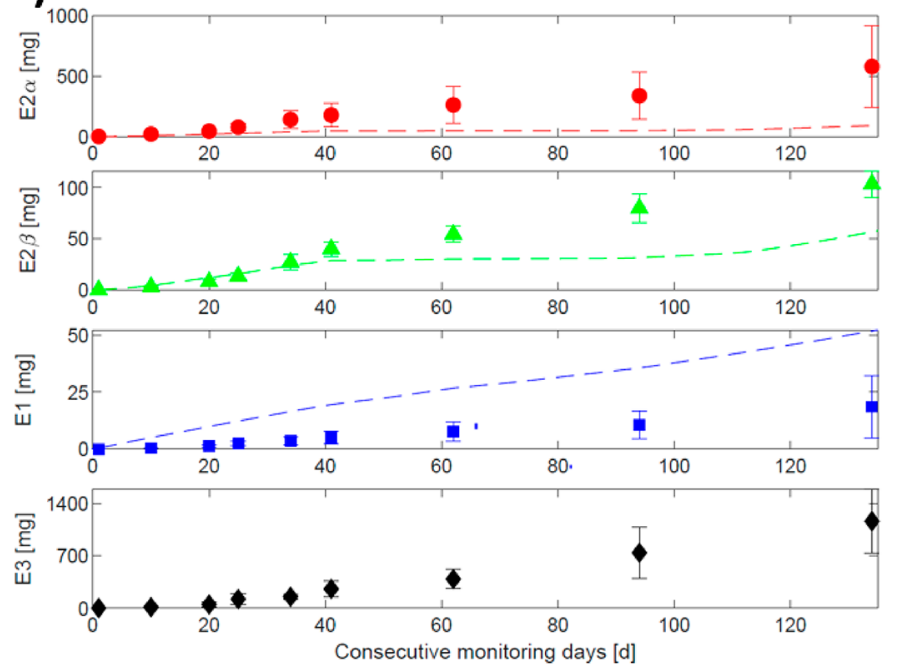

Figure 4. Measured (filled symbols) and estimated loads (based on Hoffmann et al.; ${ }^{42}$ dashed line) of nonconjugated $17 \alpha$-estradiol (E2 $\alpha$, red points), 17 $\beta$-estradiol (E2 $\beta$, green triangles), estrone (E1, blue squares), and estriol (E3, black diamonds) in the slurry cross channel (A; accumulated over eight to 10 days and then discharged into the slurry pit) and slurry pit (B; accumulated continuously over 134 days) of experimental dairy housing in Taenikon, Switzerland. Note that the scale on $y$-axis differs among substances. Error bars represent the standard deviation among the triplicate of subsamples. Note that in the slurry pit (B) plotted measured estrogen loads (filled symbols) are the cumulative sum of measured estrogen loads and hence error bars, indicating standard deviations, included error propagation calculations.

concentration during anaerobic digestion of dairy slurry in a dedicated anaerobic digester did not change significantly over time. Additionally, Zheng et al. demonstrated that under anaerobic conditions $\mathrm{E} 2 \alpha, \mathrm{E} 2 \beta$, and $\mathrm{E} 1$ in aqueous solutions blended with dairy lagoon water were transformed initially, but the concentrations stabilized after 10,20 , and 10 days, respectively. ${ }^{17}$ The longer dissipation period of E2 $\beta$ may explain the concentration difference between cross channel and slurry pit. Overall, literature findings confirm the observed stability of natural estrogens under anaerobic conditions, as assumed to prevail in our slurry pit.

Assessment of Estrogen Loads in a Dairy Housing System. Actual slurry volumes at each time point in the slurry cross channel and pit allowed translating measured estrogen concentrations into loads. In the cross channel, maximal loads per five to ten day slurry batch were $24.8,5.6,0.4$, and $29.9 \mathrm{mg}$ for $\mathrm{E} 2 \alpha, \mathrm{E} 2 \beta, \mathrm{E} 1$, and E3, respectively (Figure 4A, filled symbols). Maximal estrogen loads in the slurry pit were 578.5 $\mathrm{mg}$ of $\mathrm{E} 2 \alpha, 103.5 \mathrm{mg}$ of $\mathrm{E} 2 \beta, 18.5 \mathrm{mg}$ of $\mathrm{E} 1$, and $1159 \mathrm{mg}$ of E3 (Figure 4B, filled symbols). These loads were then compared with estimated loads of nonconjugated estrogens excreted by the Taenikon cattle herd (Figure 4A and 4B, dashed lines), using corresponding urinary and fecal estrogen concentrations for cattle in their different stages of pregnancy, ${ }^{42}$ and typical urine volumes and faeces mass excreted per day. ${ }^{43,44}$

Figure 4 reveals considerable discrepancies between measured and estimated free estrogen loads, both in the cross channel as well as in the slurry pit. While the load of E1 was generally overestimated (especially in the cross channel), the one of E2 $\alpha$ was systematically underestimated. The match was better for E2 $\alpha$ in the cross channel, but deviations increased in the slurry pit over the experiment, leading to a general underestimation by a factor of three. Measured and estimated E2 $\beta$ loads were in good agreement in the slurry cross channel (Figure 4A). Until monitoring day 42, a good fit for measured and estimated E2 $\beta$ was equally observed in the slurry pit. However, toward the end of the monitoring campaign, actually measured E2 $\beta$ loads were higher than estimated E2 $\beta$ loads (Figure 4B). Estriol was not predicted, because it is not produced in cattle and was therefore not reported by Hoffmann et al. in urine and faeces. ${ }^{42}$

Deviations between natural estrogen loads obtained from slurry analyses and those predicted from cattle excretion data and pregnancy stages ${ }^{42}$ indicate that a number of processes took place in our study which are not fully reflected by our target analytes. These include the excretion of sulfo- and glucoconjugated estrogens, ${ }^{42}$ their deconjugation, ${ }^{45,46}$ as well as metabolization pathways between natural estrogens ${ }^{13}$ over the course of slurry aging on the housing ground and in the slurry cross channel and pit. In urine estrogens are exclusively excreted as conjugates. ${ }^{42}$ While $\mathrm{E} 1$ is mainly sulfonate conjugated, E2 $\alpha$ and $\mathrm{E} 2 \beta$ are predominantly glucuronide conjugated. $^{42}$ For the interpretation of natural estrogen concentrations in slurry the additional presence of conjugated estrogens needs to be considered. For instance, in secondary dairy lagoons, $57 \%$ of the estrogens prevailed as conjugates. ${ }^{13}$ Under anaerobic conditions in sewage sludge, sulfonate conjugated estrogens were slower deconjugated (complete deconjugation after 8.3 days) than glucuronide conjugated estrogens (complete deconjugation after 1.25 days). ${ }^{45}$ In consequence, we hypothesize that deconjugation of mainly glucuronide conjugated E2 $\alpha$ and E2 $\beta$ advanced already in the channel, whereas deconjugation of sulfo-conjugated E1 mainly took place in the slurry pit. While this does not account for the general overestimation of E1 in either slurry part, it may explain the somewhat reduced deviation of E1 in the pit compared to the cross channel.

With regard to the free natural estrogens, previous studies reported that under anaerobic conditions E2 $\alpha$ and E2 $\beta$ were oxidized to E1. ${ }^{17,47}$ However, this reaction is reversible and reversion was observed under anaerobic conditions in aqueous solutions blended with dairy lagoon water (reversion of E1 to $\mathrm{E} 2 \alpha$ at $35{ }^{\circ} \mathrm{C}, k=0.013 \pm 0.001 \mathrm{~d}^{-1}$; reversion of $\mathrm{E} 1$ to $\mathrm{E} 2 \beta$ at 

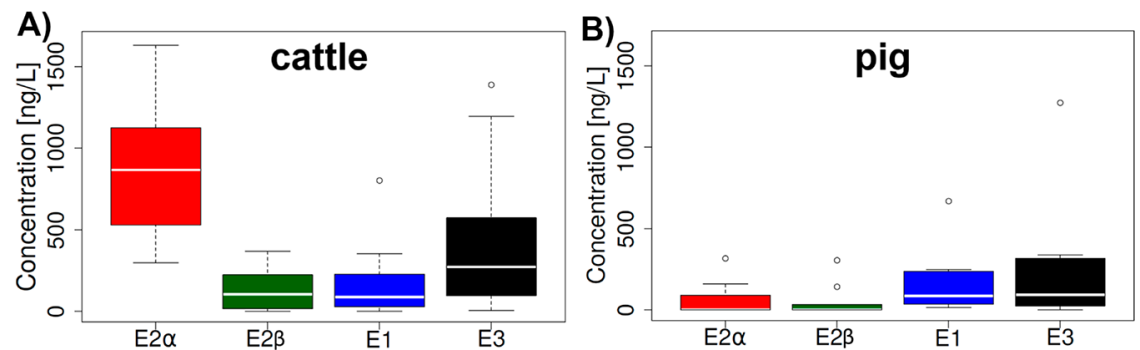

Figure 5. Concentrations of nonconjugated $17 \alpha$-estradiol (E2 $\alpha), 17 \beta$-estradiol (E2 $\beta)$, estrone (E1), and estriol (E3) in cattle (A; $n=17)$ and pig slurry $(B ; n=9)$ from Switzerland (for locations, see Figure 2). The white segment inside the rectangle shows the median estrogen concentration and whiskers above and below the box are the locations of minimal and maximal estrogen concentrations. First and third quartile are linked through a central rectangle. Empty circles represent outliers.

$\left.35{ }^{\circ} \mathrm{C}, k=0.215 \pm 0.096 \mathrm{~d}^{-1}\right) .{ }^{17}$ Additionally, E1 is degraded to E3. ${ }^{13}$ We suggest that in the cross channel and slurry pit E1 was back transformed to E2 $\alpha$ and E2 $\beta$. This is a plausible explanation for, on the one hand, E1 overestimation in the cross channel and slurry pit and, on the other hand, for E2 $\alpha$ underestimation in the cross channel and slurry pit. A further explanation for E1 overestimation is the degradation of E1 to E3.

Natural Estrogen Concentrations in Swiss Slurry Pits. The detailed and temporally highly resolved experiment in Taenikon was complemented with a nationwide husbandry animal slurry monitoring study. We assessed natural estrogen concentrations in slurry pits of nine pig fattening and 17 dairy and/or cattle fattening farms. Regarding dry matter, organic content and nutrient concentrations, the collected slurry samples were comparable to reference values in Swiss cattle and pig slurry (SI, Table S6). ${ }^{48}$ Hence, we ensured that collected slurry samples were representative for Switzerland. In cattle slurry the mean concentrations were $861 \pm 367,138 \pm$ $126,160 \pm 205$, and $397 \pm 411 \mathrm{ng} / \mathrm{L}$ for $\mathrm{E} 2 \alpha, \mathrm{E} 2 \beta, \mathrm{E} 3$, and $\mathrm{E} 1$, respectively (mean natural estrogen concentrations of every cattle slurry pit are shown in the SI, Table S4). The median concentrations measured in cattle slurries were: 900, 108,84 , and $270 \mathrm{ng} / \mathrm{L}$ for $\mathrm{E} 2 \alpha, \mathrm{E} 2 \beta, \mathrm{E} 1$, and $\mathrm{E} 3$, respectively (Figure 5A). Whereas the concentrations of $\mathrm{E} 2 \alpha$ and $\mathrm{E} 2 \beta$ were in good agreement in both studies reported here, they were on average five times higher for E1 but only half as high for E3 in the nationwide monitoring compared to the Taenikon experiment. Concentrations of $\mathrm{E} 2 \alpha, \mathrm{E} 2 \beta$, and $\mathrm{E} 1$ observed in our study (Figure 5A) were well within reported ranges in the literature, which spread widely, however, from 10 to 10500 $\mathrm{ng} / \mathrm{L}^{11,13-15}$ Estriol concentrations in cattle slurry were considerably and consistently higher though, than reported in the literature (not-detected, $<8 \mathrm{ng} / \mathrm{L}$ )..$^{1,13,15}$ It has to be noticed that, in the mentioned studies, slurry samples were collected from uncovered slotted slurry dams or slurry lagoons. As it was demonstrated in other studies, E2 $\alpha$ was the most prevalent estrogen in cattle slurry. ${ }^{14,18}$ Estriol is not produced in cattle, however, it is a microbial degradation product of E1. ${ }^{42,49}$ We assume that differences in slurry management and in slurry storage facilities housing systems might lead to different microbial regimes in Swiss husbandry animal slurry.

In the Taenikon slurry pit E2 $\alpha, \mathrm{E} 2 \beta, \mathrm{E} 1$, and E3 concentrations remained relatively stable over longer slurry storage time (Figure 3B). Storage time was defined as the timespan since the last slurry pit emptying. We hypothesized that this observation was transferable to other dairy slurry pits in Switzerland. To assess this hypothesis, we plotted slurry storage time against $\mathrm{E} 2 \alpha, \mathrm{E} 2 \beta, \mathrm{E} 1$, and $\mathrm{E} 3$ concentrations in Swiss cattle slurry pits (Figure 6). In the national slurry

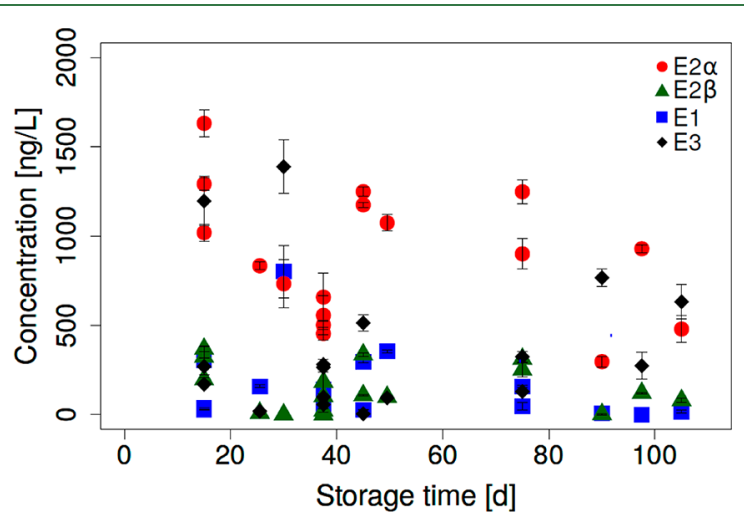

Figure 6. Concentrations of $17 \alpha$-estradiol (E2 $\alpha$, red circles), $17 \beta$ estradiol (E2 $\beta$, green triangles), estrone (E1, blue squares), and estriol (E3, black diamonds) in cattle slurries $(n=17)$ in Switzerland (for locations, see Figure 2) plotted against slurry storage time. Every slurry pit was sampled at one time point in October and November 2018. Error bars represent the standard deviation among the duplicate of subsamples.

monitoring, every slurry pit was sampled only at one time point, and storage duration was based on estimates of farmers. Similarly to Taenikon dairy slurry pit, E2 $\alpha$ and E3 concentrations were higher than $\mathrm{E} 1$ and $\mathrm{E} 2 \beta$ concentrations in the monitored Swiss cattle slurry pits. We found that with increased storage time E2 $\alpha$ concentration tended to decrease and E3 concentrations increased in cattle slurry. $17 \beta$-Estradiol concentration remained relatively stable over storage duration. Estrone concentration was temporarily augmented in cattle slurry for a storage duration of 20-50 days. In tendency, the relative contribution of $\mathrm{E} 3$ concentration to the total natural estrogen concentration in cattle slurry rose with prolonged storage time (SI, Figure S5). These temporal trends are in line with the general metabolization pathways presented by Zheng et al. ${ }^{17}$ and Hutchins et al., ${ }^{13}$ where $\mathrm{E} 2 \alpha$ and $\mathrm{E} 2 \beta$ is degraded to E1, which in turn is further transformed to E3. A more detailed data interpretation is hampered by various potentially influencing factors, such as differences in individual slurry pit construction, manure handling and dilution, as well as uncertainties in storage time estimations.

All natural estrogens, meaning $\mathrm{E} 2 \alpha, \mathrm{E} 2 \beta, \mathrm{E} 1$, and $\mathrm{E} 3$, were detected in pig slurry. The mean concentrations measured in pig slurries were $70 \pm 108,54 \pm 105,160 \pm 210$, and $244 \pm$ $406 \mathrm{ng} / \mathrm{L} \mathrm{E} 2 \alpha, \mathrm{E} 2 \beta, \mathrm{E} 1$, and E3, respectively (mean natural 


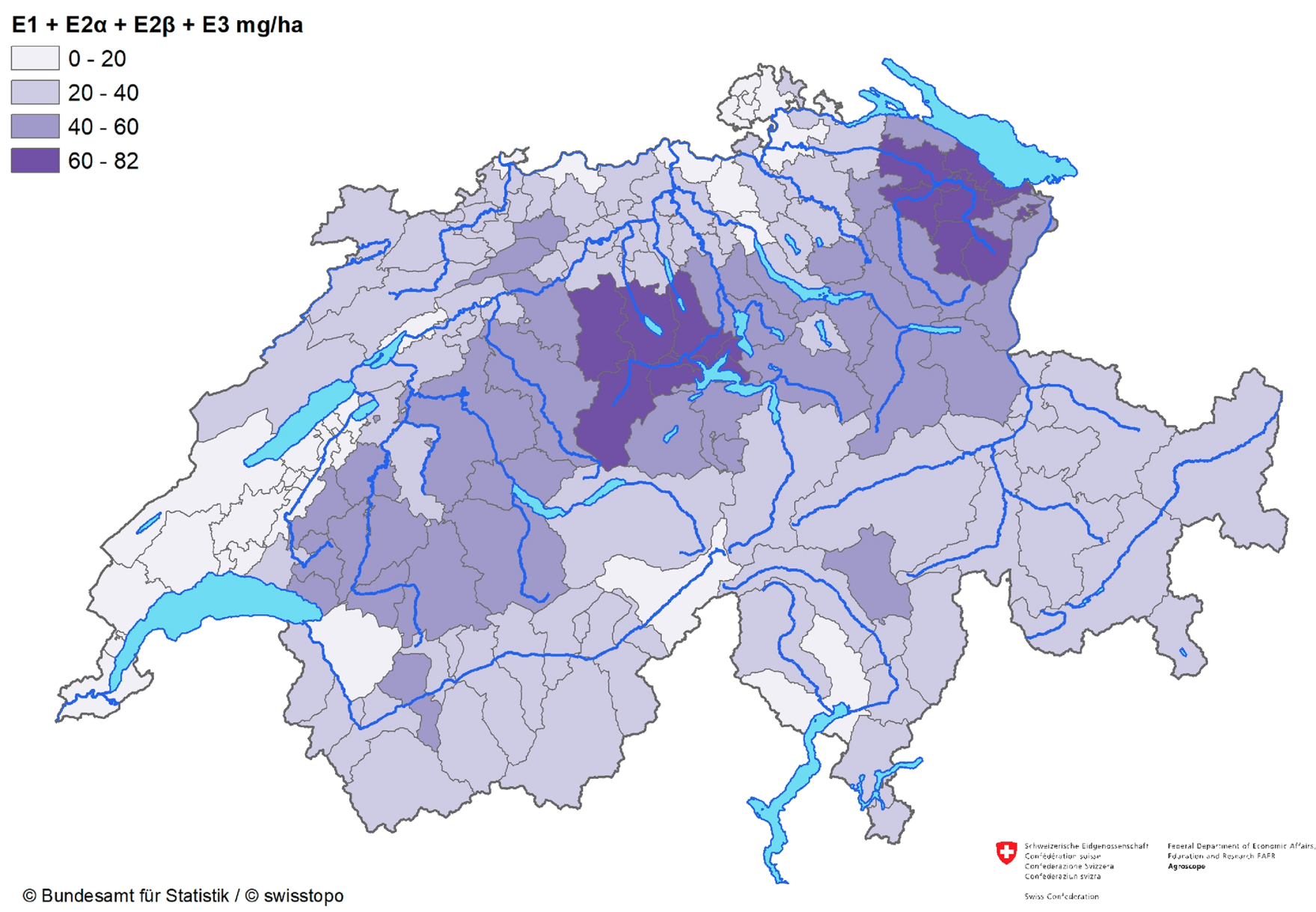

Figure 7. Average annual load of total natural estrogens $(17 \alpha$-estradiol $+17 \beta$-estradiol + estrone + estriol $)$ from pig and cattle slurry applied per hectare agricultural area on which manure is applied for every Swiss district. For details about their calculations, see main text and the SI, Chapter 8 . The calculated values were joined to landscape models, which contained administrative units, national boundaries and natural features such as watercourses and lake contours of Switzerland (Source: "Swiss Federal Office of Topography"). ${ }^{53}$

estrogen concentrations of every pig slurry pit are listed in the SI, Table S5). The median concentrations measured in pig slurries were $<\mathrm{LOQ}<\mathrm{LOQ} 85 \mathrm{ng} / \mathrm{L}$ and $93 \mathrm{ng} / \mathrm{L}$ for $\mathrm{E} 2 \alpha$, $\mathrm{E} 2 \beta, \mathrm{E} 1$, and $\mathrm{E} 3$, respectively (Figure $5 \mathrm{~B}$ ). Both the dominance of $\mathrm{E} 1$ and $\mathrm{E} 3$ (Figure $5 \mathrm{~B}$ ) and similar concentrations of E2 $\alpha$ and E2 $\beta$ (Figure 5B) are confirmed by literature. ${ }^{10,13}$ In previous studies $\mathrm{E} 2 \alpha, \mathrm{E} 2 \beta, \mathrm{E} 1$, and $\mathrm{E} 3$ concentrations in liquid pig slurry ranged from nondetected to $74700 \mathrm{ng} / \mathrm{L}^{10-14,16}$ Therewith, our results are within the reported natural estrogen concentration ranges of former studies.

Overall, the total natural estrogen concentration (E2 $\alpha+\mathrm{E} 2 \beta$ $+\mathrm{E} 1+\mathrm{E} 3)$ in pig slurry was lower than in cattle slurry. In this study mainly slurry pits of pig fattening farms were monitored. Whereas E1 and E3 occurred in similar concentrations as in cattle slurry, E2 $\alpha$ and $\mathrm{E} 2 \beta$ concentrations were significantly lower in pig slurry. Compared to dairy farms, there were no or only a few pregnant pigs on pig fattening farms. Since estrogen production and excretion in female mammals is higher during pregnancy than cycling, ${ }^{9}$ we hypothesize that the absence of pregnant individuals in pig fattening farms and species differences were the major reasons for lower total estrogen concentrations in pig slurry.

Spatially Resolved Agriculturally Derived Natural Estrogen Emissions to Soil. Finally, we calculated the total natural estrogen load emitted to Swiss agricultural area on which slurry is applied. The annual load of total estrogens
$(\mathrm{E} 2 \alpha+\mathrm{E} 2 \beta+\mathrm{E} 1+\mathrm{E} 3)$ applied on agricultural area per district (Figure 7) amounted to $36 \mathrm{mg}$ per hectare on average. Calculations are explained in detail in the SI (SI, Chapter S9). Two hotspots are discernible, which are located in central and eastern Switzerland, respectively. The former is caused by both high pig and cattle densities, the later mainly by high cattle density (SI, Figures S1 and S2). However, annually applied agriculturally derived estrogen loads per hectare agricultural area are not solely determined by husbandry animal density (Figure 2). Additionally, availability of slurry amended soil, specifically grassland and arable land, for a given district, play a role as well.

With this annual load, Switzerland would be situated in between countries like the United States ( $92 \mathrm{mg} / \mathrm{ha}$ ) and New Zealand ( $7 \mathrm{mg} / \mathrm{ha}$; for calculations and underlying literature, see the SI, Chapter 9). ${ }^{11,13,14,18}$ Differences among the results might be explainable with differences in farming systems, farm sizes, housing facilities and slurry storage among the countries, slurry analysis methods in the studies and data availability of the studied countries. In conclusion, the annual load of total estrogen applied on Swiss agricultural area is comparable to other countries.

Environmental Relevance. Based on the here reported data, we are now in a position to refine the initially estimated agricultural estrogen emissions that were based on husbandry animal excretion data from literature only (see the 
Introduction and SI, Table S1). From determined mean natural estrogen concentrations in slurry, produced slurry volume $^{48}$ and livestock numbers, ${ }^{6}$ the annually produced estrogen loads in Swiss cattle and pig slurry are now predicted to be $14 \mathrm{~kg} /$ year E2 $\alpha, 3 \mathrm{~kg} /$ year E2 $\beta, 4 \mathrm{~kg} /$ year E1, and $8 \mathrm{~kg} /$ year E3. This means that in Switzerland agriculture annually emits $3.8 \mathrm{~kg}$ of $\mathrm{E} 2 \beta$ equivalents to the environment. Translating WWTP emissions estimated for other countries $^{26,50}$ to Switzerland, they annually emit $1.5 \mathrm{~kg}$ of E2 $\beta$ and $9.7 \mathrm{~kg}$ of $\mathrm{E} 1 .^{26,50}$ Hence, $70 \%$ of the $\mathrm{E} 2 \beta$ equivalents received by the environment originate from agriculture and $30 \%$ from humans (not including E3 for humans: for details about all assumptions for this comparison, see the SI, Chapter 9). We are aware that both our data and the excretion data from literature ${ }^{5}$ only include the four deconjugated natural estrogens $\mathrm{E} 2 \alpha, \mathrm{E} 2 \beta, \mathrm{E} 1$, and E3. Conjugated ${ }^{13,42}$ and other species ${ }^{51}$ may further add to the total steroid hormone fluxes. In conclusion, we confirmed that agriculture is a source for natural estrogens in the environment and were capable to put its relative contribution into perspective. From an environmental point of view, it is noticeable that $\mathrm{E} 2 \beta$, which has the highest estrogenicity among all natural estrogens and is hence most harmful for aquatic organisms (i.e., shown by Thorpe et al. $^{52}$ ), had the lowest concentration of all measured natural estrogens in cattle and pig slurries, and consequently, the loads of E2 $\beta$ emitted were the lowest of all natural estrogens. Nonetheless, once applied to soil, transport, transformation, reversion and degradation processes of agriculturally derived estrogens are not yet entirely understood.

\section{ASSOCIATED CONTENT}

\section{(s) Supporting Information}

The Supporting Information is available free of charge at https://pubs.acs.org/doi/10.1021/acs.jafc.0c00858.

Livestock numbers per district; calculations of natural estrogen loads produced by humans and livestock in Switzerland; a schematic illustration of the experimental dairy housing in Taenikon, Switzerland; a picture of the slurry collection device; analytical methodology for estrogen determination including used chemicals, optimized LC-MS/MS parameters, description of method validation for slurry, description of nutrients, and dry matter determination in slurry; data from the slurry monitoring, i.e., tables with mean natural estrogen concentrations in Swiss pig and cattle slurry pits, concentrations of natural estrogens in pig slurry over storage time in the nationwide monitoring, relative contribution of every natural estrogen to the total estrogen concentration in cattle and pig slurry over storage time, characteristics of pig and cattle slurries; calculations for the spatially resolved agriculturally derived natural estrogen emissions to soil, maps showing the distribution of $\mathrm{E} 2 \alpha, \mathrm{E} 2 \beta, \mathrm{E} 1$, and $\mathrm{E} 3$ emissions to agricultural area in Switzerland, and table with input variables for calculations for the spatially resolved agriculturally derived natural estrogen emissions to soil. (PDF)

\section{AUTHOR INFORMATION}

\section{Corresponding Author}

Thomas D. Bucheli - Agroscope, Environmental Analytics, 8046 Zurich, Switzerland; ㅇorcid.org/0000-0001-9971-
3104; Phone: +41 5846873 42; Email: thomas.bucheli@ agroscope.admin.ch

\section{Authors}

Daniela Rechsteiner - Agroscope, Environmental Analytics, 8046 Zurich, Switzerland; Institute of Biogeochemistry and Pollutant Dynamics, ETH Zurich, 8092 Zurich, Switzerland

Sabine Schrade - Agroscope, Ruminants Research Unit, 8356 Ettenhausen, Switzerland

Michael Zähner - Agroscope, Ruminants Research Unit, 8356 Ettenhausen, Switzerland

Michael Müller - Agroscope, Swiss Soil Monitoring Network, 8046 Zurich, Switzerland

Juliane Hollender - Institute of Biogeochemistry and Pollutant Dynamics, ETH Zurich, 8092 Zurich, Switzerland; Swiss Federal Institute of Aquatic Science and Technology, Eawag, 8600 Dübendorf, Switzerland; 이이. orcid.org/0000-0002-4660$274 \mathrm{X}$

Complete contact information is available at:

https://pubs.acs.org/10.1021/acs.jafc.0c00858

\section{Funding}

We gratefully acknowledge the funding of this project by the Swiss Federal Office for the Environment (FOEN).

\section{Notes}

The authors declare no competing financial interest.

\section{ACKNOWLEDGMENTS}

We thank Felix Wettstein for helping with analytical method development. Thomas Kupper is acknowledged for the helpful discussions on slurry monitoring campaign design. A special thanks goes to Tamlyn MacLear for her help in the field during the slurry monitoring campaign. We thank Teklit Misghina for his support with slurry sample processing. We thank Manuel Schneider and Martin Schmid for their help with modelling. Lilian Gasser from statistical consulting at ETH is acknowledged for her help with statistics. Jonas Winizki is acknowledged for help given in maps creation.

\section{ABBREVIATIONS USED}

E1, estrone; E1- $\mathrm{d}_{4}$, estrone-2,4,16,16- $\mathrm{d}_{4} ; \mathrm{E} 2 \alpha, 17 \alpha$-estradiol; E2 $\alpha$ - $\mathrm{d}_{3}, 17 \alpha$-estradiol- $16,16,17-\mathrm{d}_{3} ; \mathrm{E} 2 \beta, 17 \beta$-estradiol; E2 $\beta$ - $\mathrm{d}_{3}$, $17 \beta$-estradiol-16,16,17- $\mathrm{d}_{3}$; E3, estriol; E3- $\mathrm{d}_{3}$, estriol-3,16,17- $\mathrm{d}_{3}$; FOEN, Swiss Federal Office for the Environment; LOD, limit of detection; LOQ limit of quantification; LSU, livestock units; QuEChERS, quick, easy, cheap, effective, rugged and safe; SI, Supporting Information; WWTP, wastewater treatment plant

\section{REFERENCES}

(1) Routledge, E.; Sheahan, D.; Desbrow, C.; Brighty, G.; Waldock, M.; Sumpter, J. Identification of estrogenic chemicals in STW effluent. 2. In vivo responses in trout and roach. Environ. Sci. Technol. 1998, 32 (11), 1559-1565.

(2) Vethaak, A. D.; Lahr, J.; Schrap, S. M.; Belfroid, A. C.; Rijs, G. B. J.; Gerritsen, A.; de Boer, J.; Bulder, A. S.; Grinwis, G. C. M.; Kuiper, R. V.; Legler, J.; Murk, T. A. J.; Peijnenburg, W.; Verhaar, H. J. M.; de Voogt, P. An integrated assessment of estrogenic contamination and biological effects in the aquatic environment of The Netherlands. Chemosphere 2005, 59 (4), 511-524.

(3) Olsen, P.; Bach, K.; Barlebo, H. C.; Ingerslev, F.; Hansen, M.; Sørensen, B. H. Leaching of estrogenic hormones from manure- 
treated structured soils. Environ. Sci. Technol. 2007, 41 (11), 39113917.

(4) Dutta, S.; Inamdar, S.; Tso, J.; Aga, D. S.; Sims, J. T. Free and Conjugated Estrogen Exports in Surface-Runoff from Poultry Litter. J. Environ. Qual. 2010, 39, 1688-1698.

(5) Johnson, A.; Williams, R.; Matthiessen, P. The potential steroid hormone contribution of farm animals to freshwaters, the United Kingdom as a case study. Sci. Total Environ. 2006, 362 (1), 166-178.

(6) Statistischer Atlas der Schweiz https://www.atlas.bfs.admin.ch/ maps/13/de/15070_112_7281_7263/23820.html; accessed 08/08/ 2019.

(7) Bäni, H. Alles für die Katz https://www.srf.ch/sendungen/dok/ alles-fuer-die-katz; accessed 03/13/2020.

(8) Jagdstatistik. https://www.jagdstatistik.ch/de/statistics?tt= $0 \& \mathrm{dt}=0 \& \mathrm{at}=0 \& \mathrm{st}=0 \& \mathrm{dp}=0 \& \mathrm{ar}=\mathrm{CH} \& \mathrm{th}=1 \& \mathrm{yr} \% 5 \mathrm{~B}$ from $\% 5 \mathrm{D}=$ 2015\&yr\%5Bto\%5D=2018\&sp=\%2016; accessed 03/13/2020.

(9) Döcke, F. Veterinärmedizinische Endokrinologie; G. Fischer: 1975. (10) Furuichi, T.; Kannan, K.; Suzuki, K.; Tanaka, S.; Giesy, J. P.; Masunaga, $\mathrm{S}$. Occurrence of estrogenic compounds in and removal by a swine farm waste treatment plant. Environ. Sci. Technol. 2006, 40 (24), 7896-7902.

(11) Sarmah, A.; Northcott, G.; Leusch, F.; Tremblay, L. A survey of endocrine disrupting chemicals (EDCs) in municipal sewage and animal waste effluents in the Waikato region of New Zealand. Sci. Total Environ. 2006, 355 (1-3), 135-144.

(12) Shappell, N. W.; Billey, L. O.; Forbes, D.; Matheny, T. A.; Poach, M. E.; Reddy, G. B.; Hunt, P. G. Estrogenic activity and steroid hormones in swine wastewater through a lagoon constructedwetland system. Environ. Sci. Technol. 2007, 41 (2), 444-450.

(13) Hutchins, S. R.; White, M. V.; Hudson, F. M.; Fine, D. D. Analysis of lagoon samples from different concentrated animal feeding operations for estrogens and estrogen conjugates. Environ. Sci. Technol. 2007, 41 (3), 738-744.

(14) Raman, D. R.; Williams, E. L.; Layton, A. C.; Burns, R. T.; Easter, J. P.; Daugherty, A. S.; Mullen, M. D.; Sayler, G. S. Estrogen content of dairy and swine wastes. Environ. Sci. Technol. 2004, 38 (13), 3567-3573.

(15) Zheng, W.; Yates, S. R.; Bradford, S. A. Analysis of steroid hormones in a typical dairy waste disposal system. Environ. Sci. Technol. 2008, 42 (2), 530-535.

(16) Fine, D. D.; Breidenbach, G. P.; Price, T. L.; Hutchins, S. R. Quantitation of estrogens in ground water and swine lagoon samples using solid-phase extraction, pentafluorobenzyl/trimethylsilyl derivatizations and gas chromatography-negative ion chemical ionization tandem mass spectrometry. J. Chrom. A 2003, 1017 (1-2), 167-185.

(17) Zheng, W.; Li, X.; Yates, S. R.; Bradford, S. A. Anaerobic transformation kinetics and mechanism of steroid estrogenic hormones in dairy lagoon water. Environ. Sci. Technol. 2012, 46 (10), 5471-5478.

(18) Noguera-Oviedo, K.; Aga, D. S. Chemical and biological assessment of endocrine disrupting chemicals in a full scale dairy manure anaerobic digester with thermal pretreatment. Sci. Total Environ. 2016, 550, 827-834.

(19) Combalbert, S.; Hernandez-Raquet, G. Occurrence, fate, and biodegradation of estrogens in sewage and manure. Appl. Microbiol. Biotechnol. 2010, 86 (6), 1671-1692.

(20) Yang, Y.-Y.; Borch, T.; Young, R. B.; Goodridge, L. D.; Davis, J. G. Degradation kinetics of testosterone by manure-borne bacteria: Influence of temperature, $\mathrm{pH}$, glucose amendments, and dissolved oxygen. J. Environ. Qual. 2010, 39 (4), 1153-1160.

(21) Zheng, W.; Zou, Y.; Li, X.; Machesky, M. L. Fate of estrogen conjugate $17 \alpha$-estradiol-3-sulfate in dairy wastewater: Comparison of aerobic and anaerobic degradation and metabolite formation. J. Hazard. Mater. 2013, 258, 109-115.

(22) Raman, D. R.; Layton, A. C.; Moody, L. B.; Easter, J. P.; Sayler, G. S.; Burns, R. T.; Mullen, M. Degradation of estrogens in dairy waste solids: Effects of acidification and temperature. Trans ASAE 2001, 44 (6), 1881.
(23) eurostat Statistics Explained https://ec.europa.eu/eurostat/ statistics-explained/index.php/Agri-environmental_indicator_livestock patterns; accessed 11/28/2019.

(24) Federal Office for the Environment and Federal Office for Agriculture, Baulicher Umweltschutz in der Landwirtschaft. Ein Modul der Vollzugshilfe Umweltschutz in der Landwirtschaft. Bundesamtes für Umwelt, Bern 2011, Umwelt-Vollzug Nr. 1101, 123.

(25) National Agricultural Statistics Service NASS, Quick Stats; http://quickstats.nass.usda.gov/; accessed 01/21/2020.

(26) Margot, J.; Kienle, C.; Magnet, A.; Weil, M.; Rossi, L.; de Alencastro, L. F.; Abegglen, C.; Thonney, D.; Chèvre, N.; Schärer, M.; Barry, D. A. , Treatment of micropollutants in municipal wastewater: Ozone or powdered activated carbon? Sci. Total Environ. 2013, 461$462,480-498$.

(27) Verordnung über die Direktzahlungen an die Landwirtschaft. https://www.admin.ch/opc/de/classified-compilation/20130216/ index.html; accessed 03/16/2020.

(28) Agrarbericht 2019. https://www.agrarbericht.ch/de/politik/ direktzahlungen/produktionssystembeitraege; accessed 03/27/2020.

(29) Kupper, T. Ammonia emissions from agriculture in Switzerland for 1990 to 2015. https://www.agrammon.ch/assets/Downloads/ Bericht Agrammon 1990-2015 20181010.pdf; accessed 03/16/ 2020.

(30) Alder, S.; Prasuhn, V.; Liniger, H.; Herweg, K.; Hurni, H.; Candinas, A.; Gujer, H. U. A high-resolution map of direct and indirect connectivity of erosion risk areas to surface waters in Switzerland-a risk assessment tool for planning and policy-making. Land use policy 2015, 48, 236-249.

(31) Mohn, J.; Zeyer, K.; Keck, M.; Keller, M.; Zähner, M.; Poteko, J.; Emmenegger, L.; Schrade, S. A dual tracer ratio method for comparative emission measurements in an experimental dairy housing. Atmos. Environ. 2018, 179, 12-22.

(32) Federal Office for the Environment. Anteil der Nutzrassen und -sorten. https://www.biodiversitymonitoring.ch/fileadmin/user upload/documents/daten/basisdaten_dt/1260_Z2_Basisdaten_ 2013 vl.pdf; accessed 01/15/2020.

(33) Animal Welfare Act. https://www.admin.ch/opc/en/classifiedcompilation/20022103/index.html; accessed 11/05/2019.

(34) Federal Act on the Protection of Waters https://www.admin. ch/opc/en/classified-compilation/19910022/index.html; accessed $01 / 19 / 2020$.

(35) Ordinance on the Reduction of Risks relating to the Use of Certain Particularly Dangerous Substances, Preparations and Articles. https://www.admin.ch/opc/en/classified-compilation/20021520/ index.html; accessed 02/05/2020.

(36) Anastassiades, M.; Lehotay, S. J.; Štajnbaher, D.; Schenck, F. J. Fast and easy multiresidue method employing acetonitrile extraction/ partitioning and "dispersive solid-phase extraction" for the determination of pesticide residues in produce. J. AOAC Int. 2003, 86 (2), $412-431$.

(37) Anari, M. R.; Bakhtiar, R.; Zhu, B.; Huskey, S.; Franklin, R. B.; Evans, D. C. Derivatization of ethinylestradiol with dansyl chloride to enhance electrospray ionization: application in trace analysis of ethinylestradiol in rhesus monkey plasma. Anal. Chem. 2002, 74 (16), 4136-4144.

(38) Backe, W. J. An Ultrasensitive (Parts-Per-Quadrillion) and SPE-Free Method for the Quantitative Analysis of Estrogens in Surface Water. Environ. Sci. Technol. 2015, 49 (24), 14311-14318.

(39) Szarka, S.; Nguyen, V.; Prokai, L.; Prokai-Tatrai, K. Separation of dansylated $17 \beta$-estradiol, $17 \alpha$-estradiol, and estrone on a single HPLC column for simultaneous quantitation by LC-MS/MS. Anal. Bioanal. Chem. 2013, 405 (10), 3399-3406.

(40) Federal Office for Statistics, Die Bodennutzung der Schweiz. Arealstatistik Schweiz 2004/2009.

(41) Team, R. C. A language and environment for statistical computing; R Foundation for Statistical Computing: Vienna, Austria, 2012; https://www.r-project.org/; accessed 02/05/2020.

(42) Hoffmann, B.; de Pinho, T. G.; Schuler, G. Determination of free and conjugated oestrogens in peripheral blood plasma, feces and 
urine of cattle throughout pregnancy. Exp. Clin. Endocrinol. Diabetes 1997, 105 (05), 296-303.

(43) Dirksen, G.; Gründer, H.-D.; Stöber, M. Die klinische Untersuchung des Rindes; Parey: 1990.

(44) Selbie, D. R.; Buckthought, L. E.; Shepherd, M. A. The challenge of the urine patch for managing nitrogen in grazed pasture systems. In Adv. Agron.; Elsevier: Amsterdam, 2015; Vol. 129, pp 229-292.

(45) D’Ascenzo, G.; Di Corcia, A.; Gentili, A.; Mancini, R.; Mastropasqua, R.; Nazzari, M.; Samperi, R. Fate of natural estrogen conjugates in municipal sewage transport and treatment facilities. Sci. Total Environ. 2003, 302 (1-3), 199-209.

(46) Isobe, T.; Shiraishi, H.; Yasuda, M.; Shinoda, A.; Suzuki, H.; Morita, M. Determination of estrogens and their conjugates in water using solid-phase extraction followed by liquid chromatographytandem mass spectrometry. J. Chrom. A 2003, 984 (2), 195-202.

(47) Xuan, R.; Blassengale, A. A.; Wang, Q. Degradation of estrogenic hormones in a silt loam soil. J. Agric. Food Chem. 2008, 56 (19), 9152-9158.

(48) Richner, W.; Sinaj, S.; Carlen, C.; Flisch, R.; Gilli, C.; Huguenin-Elie, O.; Kuster, T.; Latsch, A.; Mayer, J.; Neuweiler, R. Grundlagen für die Düngung landwirtschaftlicher Kulturen in der Schweiz (GRUD 2017). Agrarforschung Schweiz 2017, 8 (6), 47-66. (49) Järvenpää, P.; Kosunen, T.; Fotsis, T.; Adlercreutz, H. In vitro metabolism of estrogens by isolated intestinal micro-organisms and by human faecal microflora. J. Steroid Biochem. 1980, 13 (3), 345-349. (50) Arlos, M. J.; Parker, W. J.; Bicudo, J. R.; Law, P.; Marjan, P.; Andrews, S. A.; Servos, M. R. Multi-year prediction of estrogenicity in municipal wastewater effluents. Sci. Total Environ. 2018, 610-611, $1103-1112$.

(51) Lange, I. G.; Daxenberger, A.; Schiffer, B.; Witters, H.; Ibarreta, D.; Meyer, H. H. Sex hormones originating from different livestock production systems: fate and potential disrupting activity in the environment. Anal. Chim. Acta 2002, 473 (1), 27-37.

(52) Thorpe, K. L.; Cummings, R. I.; Hutchinson, T. H.; Scholze, M.; Brighty, G.; Sumpter, J. P.; Tyler, C. R. Relative potencies and combination effects of steroidal estrogens in fish. Environ. Sci. Technol. 2003, 37 (6), 1142-1149.

(53) Federal Institute of Topography. https://shop.swisstopo.admin. $\mathrm{ch} /$ en/products/landscape; accessed 03/13/2020. 